\title{
Bazı Haşhaş (Papaver somniferum L.) Çeşit ve Genotiplerinin Alkaloid ve Yağ Oranlarının Belirlenmesi
}

\author{
Levent YAZİI ${ }^{1} \quad$ Güngör YILMAZ Ylai GÖKALP $^{1}$ \\ ${ }^{1}$ Orta Karadeniz Geçit Kuşağı Tarımsal Araştırma Enstitüsü Müdürlüğü-Tokat \\ ${ }^{2}$ Gaziosmanpaşa Üniversitesi \\ $\bowtie$ : leventyzc@gmail.com
}

Geliş (Received): 04.11.2017

Kabul (Accepted): 15.12.2017

\begin{abstract}
ÖZET: Bu çalışmanın amacı, bazı haşhaş (Papaver somniferum L.) çeşit ve genotiplerinin kapsüllerinde morfin, kodein, oripavin, tebain, noskapin ve papaverin gibi ana alkaloidler ile tohumlarındaki yağ oranlarını belirlemektir. Araştırmada farklı kuruluşlardan temin edilmiş, 3 adet haşhaş çeşidi (Afyon 95, Ofis 3 ve Ofis 8) ile 94 adet genotip materyal olarak kullanılmıştır. Çalışma Tokat-Kazova şartlarında Orta Karadeniz Geçit Kuşağı Tarımsal Araştırma Enstitüsü Müdürlüğüne ait deneme tarlasında 2016 yılında yürütülmüştür. Alkaloid analizleri Bolvadin Alkaloid Fabrikası Laboratuvarında HPLC cihazında yapılmıştır. Araştırmadan elde edilen sonuçlara göre; standart olarak kullanılan çeşitlerin, ortalama morfin oranı \% 0.53-0.58, kodein \% 0.02-0.08, oripavin, \% 0.0005-0.005, tebain \% 0.006-0.02, noskapin \% 0.02-0.19, papaverin \% 0.01-0.09 ve yağ oranları ise \% 48-49 arasında değişmiştir. Genotiplerin ortalama morfin oran $1 \% 0.15-0.60$, kodein $\% 0.001-0.21$, oripavin $\% 0-0.01$, tebain $\% 0.001-0.08$, noskapin \% 0.005-0.20, papaverin \% 0.004-0.21 ve yağ oranları ise \% 40-53 arasında değişmiştir.

Anahtar Kelimeler: Haşhaş, Papaver somniferum L., alkaloid, yă̆g,
\end{abstract}

\section{Determination of Alkaloids and Oil Rates of Some Poppy (Papaver somniferum L.) Varieties and Genotypes}

\begin{abstract}
The aim of this study is to determine of oil rates with main alkaloid in the capsules of some poppy (Papaver somniferum L.) varieties and genotypes such as morphine, codeine, oripavine, thebaine, noscapine and papaverine. Three varieties (Afyon 95, Ofis 3 ve Ofis 8) with 94 genotypes of poppy registered of different organizations were used in the research. The study was carried out in the trial field belonging to Tokat Middle Black Sea Crossing Belt Agricultural Research Institute Directorate under Tokat-Kazova conditions in 2016. Alkaloid analyzes were carried out on an HPLC device in the Bolvadin Alkaloid Plant Laboratory. As a result; varieties of poppy the mean morphine value varied between 0.53 and $0.58 \%$, the codeine 0.02 and $0.08 \%$, the oripavine 0.0005 and $0.005 \%$, the thebaine 0.006 and $0.02 \%$, the noscapine 0.02 and $0.19 \%$, the papaverine 0.01 and 0.09 and oil ratio varied between 48 and $49 \%$. The poppy genotypes had mean morphine value between 0.15 and $0.60 \%$, the codeine 0.001 and $0.21 \%$, the oripavine 0 and $0.01 \%$, the thebaine 0.001 and $0.08 \%$, the noscapine 0.005 and 0.20 $\%$, the papaverine 0.004 and $0.21 \%$, and oil ratio varied between 40 and $53 \%$.

Key words: Poppy, Papaver somniferum L., alkaloid, oil
\end{abstract}

\section{GíRIŞ}

Geleneksel olarak tarımı yapılan haşhaş, Papaver somniferum L. türü olan tek yıllık bir kültür bitkisidir. Papaver somniferum L., Rhoedales takımının Papaveraceae familyasindandir. Papaveraceae familyası papaver cinsi içerisinde son düzenlemeler ile ülkemizde 28 tür, 18 tür altı takson tespit edilmiştir (Davis et al.1988, Anonim, 2017).

Dünyada tıbbi amaçlarla afyon ve afyon alkaloidlerini elde etmek amacıyla yapılan haşhaş tarımı, Birleşmiş Milletler Teşkilatı denetiminde, yasal ana üretici olarak Türkiye, Hindistan, Avustralya, İspanya, Fransa ve Macaristan'da yapılmaktadır. Üretim Hindistan'da afyon sakızı, diğer ülkelerde ise kuru haşhaş kapsülü şeklinde yapılmaktadır.

Dünya'da en önemli haşhaş üreticisi devletler arasında olan Türkiye'de haşhaş ekimi, Birleşmiş Milletler Teşkilatınca ülkemize verilen 70 bin hektar limit dahilinde, Bakanlar Kurulunca haşhaş ekimine müsaade edilen yerlerde ve Toprak Mahsulleri Ofisi Genel Müdürlüğünce yapılan planlama çerçevesinde lisansa tabi, kontrollü ve çizilmemiş kuru haşhaş kapsülü üretimi şeklinde yapılmaktadır. 2016/2017 tarım döneminde ekim kışlık ve yazlık olarak, Afyonkarahisar, Denizli, Konya, Burdur, Uşak, Isparta, Eskişehir, Kütahya, Manisa, Balıkesir, Çorum, Amasya ve Tokat illerinde gerçekleşmiştir. Söz konusu 70.000 hektar ekim limiti, ekiliş ve üretim potansiyelleri dikkate alınarak yerleşim birimlerine dağıtılmaktadır. Yerleşim birimi bazında verilen haşhaş ekim limitleri çiftçilere paylaştırılarak bu limit çerçevesinde bir çiftçiye en fazla 3 tarlasında haşhaş ekim izni verilmektedir (Anonim, 2017).

Ülkemizde geleneksel haşhaş ürününü değerlendirmek ve piyasanın yasal alkaloid gereksinimini karşılamak amacıyla kurulan Afyon Alkaloidleri Fabrikasında 25.000 ton/y1l çizilmemiş kuru haşhaş kapsülü işleme kapasitesiyle kapsüldeki morfin oranına bağlı olmakla birlikte yılda 80-100 ton civarında morfin üretimi gerçekleştirilmektedir. Üretilen morfin ve türevlerinin $\% \quad 5$ yurt içinde ilaç endüstrisinde, $\%$ 95'i tıbbi amaçlı olarak ihraç 
edilmektedir. İhracatın \% 85'i ABD’ye, kalan kısmı da Asya, Avrupa ve Afrika ülkelerine olmaktadır. Dünyada haşhaş kökenli tıbbi ve bilimsel amaçlı uyuşturucu madde tüketimi yılda yaklaşık 450-500 ton civarındadır. Türkiye, bu pazar payının yaklaşık \% 20'ne sahip bulunmaktadir (Anonim, 2015).

Haşhaş kapsülünün morfin, kodein, tebain, noskapin ve papaverin gibi tıbbi öneme sahip olan ana alkaloidlerin yanı sıra yaklaşık 30 değişik alkaloid ihtiva ettiği, yapılan son çalışmalar ile yaklaşık 40'a yakın alkaloidin bulunduğu tespit edilmiştir (Valızadeh, 2015).

Türkiye'de haşhaş tohumu serbest piyasa şartlarında işlem görmektedir. Türkiye'nin yıllık 25 bin ton haşhaş tohumu üretimine karşılık yılda 40 bin ton civarında ihracat potansiyeli bulunmaktadır. Haşhaş tohumunun en önemli özelliği \% 45-55 yağ ve \% 20-30 protein içeriğine sahip olmasıdır. Tohum geleneksel olarak gıda amaçlı ekmeklerde ve ezilerek hamur işlerinde kullanılmaktadır. Tohumun preslenmesi ile elde edilen yăg mutfakta ve gıda sanayisinde kullanılmaktadır. Ayrıca kozmetik ve boya sanayinde de kullanıldığ bilinmektedir (Kahraman, 2011).

$\mathrm{Bu}$ çalışmanın amacı, bazı haşhaş (Papaver somniferum L.) çeşit ve genotiplerinin kapsüllerinde morfin, kodein, oripavin, tebain, noskapin ve papaverin gibi ana alkaloidler ile tohumlarındaki yağ oranlarını belirlemektir.

\section{MATERYAL ve YÖNTEM}

$\mathrm{Bu}$ araştırmada, farklı kuruluşlardan temin edilmiş, standart olarak 3 adet haşhaş çeşidi (Afyon 95, Ofis 3 ve Ofis 8) ile 94 adet genotip materyal olarak kullanılmıştır. Deneme Tokat-Kazova şartlarında Orta Karadeniz Geçit Kuşağı Tarımsal Araştırma Enstitüsü Müdürlügüne ait deneme tarlasında 2016 yılında yürütülmüştür. Ekim 14.10.2015 tarihinde kışlık olarak yapılmıştır. Araştırmada çeşit ve genotipler $3 \mathrm{~m}$ boyunda 2 sira, $45 \mathrm{~cm}$ sıra arası, sıra üzeri daha sonra seyretme ile $10 \mathrm{~cm}$ olarak ayarlanmıştır. Hasat 18.07.2016 tarihinde deneme alanındaki tüm kapsüllerin olgunlaşması ile el ile koparılarak yapılmıştır. Yağ analizleri iki tekrarlı olarak Orta Karadeniz Geçit Kuşağı Tarımsal Araştırma Enstitüsü'nde ekstraksiyon metodu ile soksolet cihazında, alkaloid analizleri Bolvadin Alkaloid Fabrikası Laboratuvarında HPLC cihazında yapılmıştır. Haşhaş bitkisinin vejetasyon gelişimi süresince gübreleme, tekleme, sulama, çapalama gibi bakım işlemleri ve gerek görüldükçe hastalık, zararlılara karşı mücadele yapılmıştır. Ekim sirasında $6 \mathrm{~kg} / \mathrm{da} \mathrm{N}$ olacak şekilde 20-20-0 Kompoze NP gübresi ve 1 . çapa öncesinde de $6 \mathrm{~kg} / \mathrm{da} \mathrm{N}$ olacak şekilde AN (Amonyum Nitrat) gübresi uygulanmıştır (Aytekin, 2005).

\section{BULGULAR ve TARTISMA}

Denemede kullanılan çeşit ve genotiplerin alkaloid (morfin, kodein, oripavin, tebain, noskapin ve papaverin) ve yağ oranlarının ortalama değerleri ile istatistik analizler Çizelge 1'de verilmiştir.

Çizelge 1'den görüleceği gibi, standart çeşitler ile genotiplerin ortalama morfin oranı değerleri karşılaştırıldığında istatistiksel olarak önemli bulunmuştur. Çeşitlerin morfin oranı değeri, \% 0.530.58 , genotiplerin morfin oranı değeri \% 0.16-0.60 arasında değişmiştir. Genotipler arasında en yüksek morfin oranı değeri \% 0.60 ile AÜZF-22 no'lu, en düşük morfin oranı ise AÜZF 41 no'lu genotiplerde bulunmuştur. Daha önce yapılan çalışmalarda, Erdurmuş (1989), haşhaşta morfin oranını \% 0.32 - 0.82 arasında, Novak ve Strakova (1989), 20 haşhaş çeşidinde yürüttükleri bir çalışmada morfin oranı \% 0.66-0.75 arasında, Arslan (2000), değişik yörelerinden toplanan haşhaş numunelerinde 353 adedinde morfin analizleri yapılmış, morfin oranı \% $0.25-0.89$ arasında bulmuştur. Çalışmamız bu araştırmalardan elde edilen sonuçlara büyük benzerlik göstermektedir.

Çeşit ve genotiplerin ortalama kodein oranı değerleri karşılaştırıldığında anlamlı bir fark bulunmuştur. Çeşitlerin kodein oranları değerleri \% $\quad 0.02-0.04$ arasında, genotiplerin kodein oranı değerleri \% $0-0.19$ arasında değişmiştir. Genotipler arasında en yüksek kodein oranı değeri \% 0.19 ile AÜZF-5 no'lu, en düşük kodein oranı ise AÜZF 99 ve 100 no'lu genotiplerde bulunmuştur Araştırmada 79 adet hat çeşitlerin ortalama kodein oranı değeri (\% 0.03) üzerinde yer almıştır. Subrtova ve ark. (1989), seçilmiş haşhaş populasyonlarında 25 haşhaş çeşidinde yapmış oldukları denemede, kodein içeriğini en düşük \% 0 , en yüksek $\%$ 0.39 olarak tespit etmişlerdir.

Çeşit ve genotiplerin, ortalama oripavin oranı değerleri karşılaştırıldığında anlamlı bir farkın olduğu ortaya çıkmıştır. Çeşitlerin oripavin oranı değeri \% 0 0.01 , genotiplerin oripavin oranı değeri $\%$ 0.0-0.01 arasında değişmiştir. Genotipler arasında en yüksek oripavin oranı değeri \% 0.01 ile AÜZF-11, AÜZF-82, AÜZF-90, AÜZF-91, AÜZF-92, AÜZF-96, AÜZF-98no'lu genotipler olmuştur.

Çeşit ve genotiplerin ortalama tebain oranı değerleri karşılaştırıldığında anlamlı bir fark bulunmuştur. Çeşitlerin tebain oranları değerleri \% $0.01-0.03$ arasında, genotiplerin tebain oranı değerleri \% 0.00-0.08 arasında değişmiştir. Genotipler arasında en yüksek tebain oranı değeri \% 0.08 ile AÜZF-20 ve 71 no'lu genotip olmuştur. Araştırmada 33 adet genotip çeşitlerin ortalama tebain oranı değeri $(\% \quad 0.02)$ üzerinde yer almıştır. Subrtova ve ark. (1989), seçilmiş haşhaş populasyonlarında 25 haşhaş çeşidinde yapmış oldukları denemede, tebain içeriğini en düşük \% 0 , en yüksek $\%$ 0.35; olarak tespit etmişlerdir. 
Çizelge 1. Çeşit ve genotiplerin alkaloid ve yağ oranlarına iliş̧in ortalama değerler ile istatistik analizler

\begin{tabular}{|c|c|c|c|c|c|c|c|}
\hline $\begin{array}{l}\text { Çeşit/ } \\
\text { Genotip }\end{array}$ & $\begin{array}{l}\text { Morfi } \\
\text { n } \\
\text { Oranı } \\
(\%) \\
\end{array}$ & $\begin{array}{l}\text { Kodein } \\
\text { Oranı } \\
(\%)\end{array}$ & $\begin{array}{l}\text { Orp. } \\
\text { Oranı } \\
(\%)\end{array}$ & $\begin{array}{l}\text { Teb. } \\
\text { Oran } \\
1(\%)\end{array}$ & $\begin{array}{l}\text { Pap. } \\
\text { Ora } \\
\text { nı } \\
(\%)\end{array}$ & $\begin{array}{l}\text { Nos. } \\
\text { Oran } \\
\mathbf{1}(\%)\end{array}$ & $\begin{array}{l}\text { Yăg } \\
\text { Oranı } \\
(\%)\end{array}$ \\
\hline Afyon 95 & 0.58 & 0.02 & 0.01 & 0.01 & 0.01 & 0.20 & 49.00 \\
\hline Ofis 3 & 0.53 & 0.04 & 0.00 & 0.02 & 0.01 & 0.02 & 48.00 \\
\hline Ofis 8 & 0.54 & 0.08 & 0.00 & 0.03 & 0.10 & 0.12 & 48.00 \\
\hline AÜZF-1 & 0.31 & 0.18 & 0.00 & 0.04 & 0.08 & 0.12 & 48.33 \\
\hline AÜZF-2 & 0.28 & 0.18 & 0.00 & 0.02 & 0.09 & 0.04 & 48.33 \\
\hline AÜZF-3 & 0.35 & 0.17 & 0.00 & 0.02 & 0.11 & 0.04 & 46.00 \\
\hline AÜZF-4 & 0.29 & 0.14 & 0.00 & 0.01 & 0.08 & 0.05 & 53.00 \\
\hline AÜZF-5 & 0.35 & 0.19 & 0.00 & 0.04 & 0.09 & 0.09 & 45.67 \\
\hline AÜZF-7 & 0.26 & 0.14 & 0.00 & 0.01 & 0.05 & 0.10 & 46.33 \\
\hline AÜZF-8 & 0.29 & 0.16 & 0.00 & 0.01 & 0.09 & 0.06 & 45.33 \\
\hline AÜZF-9 & 0.25 & 0.15 & 0.00 & 0.01 & 0.06 & 0.05 & 44.33 \\
\hline AÜZF-10 & 0.23 & 0.14 & 0.00 & 0.01 & 0.06 & 0.05 & 46.00 \\
\hline AÜZF-11 & 0.50 & 0.15 & 0.01 & 0.00 & 0.01 & 0.11 & 46.67 \\
\hline AÜZF-12 & 0.27 & 0.14 & 0.00 & 0.00 & 0.06 & 0.03 & 44.67 \\
\hline AÜZF-13 & 0.27 & 0.14 & 0.00 & 0.00 & 0.07 & 0.06 & 46.00 \\
\hline AÜZF-14 & 0.17 & 0.12 & 0.00 & 0.02 & 0.02 & 0.03 & 49.33 \\
\hline AÜZF-15 & 0.19 & 0.15 & 0.00 & 0.05 & 0.03 & 0.02 & 49.00 \\
\hline AÜZF-16 & 0.17 & 0.16 & 0.00 & 0.06 & 0.07 & 0.03 & 43.67 \\
\hline AÜZF-17 & 0.31 & 0.16 & 0.00 & 0.05 & 0.05 & 0.07 & 46.33 \\
\hline AÜZF-18 & 0.27 & 0.16 & 0.00 & 0.00 & 0.07 & 0.08 & 49.33 \\
\hline AÜZF-19 & 0.20 & 0.17 & 0.00 & 0.04 & 0.04 & 0.03 & 48.67 \\
\hline AÜZF-20 & 0.18 & 0.15 & 0.00 & 0.08 & 0.03 & 0.03 & 48.33 \\
\hline AÜZF-21 & 0.22 & 0.03 & 0.00 & 0.02 & 0.02 & 0.03 & 47.67 \\
\hline AÜZF-22 & 0.60 & 0.09 & 0.00 & 0.04 & 0.21 & 0.17 & 46.67 \\
\hline AÜZF-23 & 0.27 & 0.05 & 0.00 & 0.03 & 0.07 & 0.06 & 46.00 \\
\hline AÜZF-24 & 0.41 & 0.05 & 0.00 & 0.02 & 0.01 & 0.05 & 51.00 \\
\hline AÜZF-25 & 0.34 & 0.05 & 0.00 & 0.02 & 0.04 & 0.04 & 45.00 \\
\hline AÜZF-26 & 0.30 & 0.05 & 0.00 & 0.02 & 0.01 & 0.04 & 40.33 \\
\hline AÜZF-27 & 0.24 & 0.04 & 0.00 & 0.01 & 0.02 & 0.08 & 44.00 \\
\hline AÜZF-28 & 0.31 & 0.04 & 0.00 & 0.02 & 0.05 & 0.05 & 43.00 \\
\hline AÜZF-29 & 0.26 & 0.04 & 0.00 & 0.02 & 0.07 & 0.05 & 44.33 \\
\hline AÜZF-30 & 0.25 & 0.05 & 0.00 & 0.02 & 0.05 & 0.06 & 42.67 \\
\hline AÜZF-31 & 0.29 & 0.12 & 0.00 & 0.07 & 0.01 & 0.08 & 42.33 \\
\hline AÜZF-32 & 0.33 & 0.03 & 0.00 & 0.01 & 0.07 & 0.07 & 43.67 \\
\hline AÜZF-33 & 0.27 & 0.04 & 0.00 & 0.01 & 0.05 & 0.04 & 46.00 \\
\hline AÜZF-34 & 0.34 & 0.05 & 0.00 & 0.01 & 0.08 & 0.05 & 46.67 \\
\hline AÜZF-35 & 0.18 & 0.03 & 0.00 & 0.02 & 0.05 & 0.02 & 46.33 \\
\hline AÜZF-36 & 0.30 & 0.06 & 0.00 & 0.03 & 0.02 & 0.05 & 42.67 \\
\hline AÜZF-39 & 0.32 & 0.05 & 0.00 & 0.00 & 0.04 & 0.05 & 45.33 \\
\hline AÜZF-40 & 0.30 & 0.05 & 0.00 & 0.02 & 0.04 & 0.04 & 46.67 \\
\hline AÜZF-41 & 0.16 & 0.04 & 0.00 & 0.01 & 0.05 & 0.04 & 48.00 \\
\hline AÜZF-42 & 0.30 & 0.05 & 0.00 & 0.01 & 0.07 & 0.08 & 45.00 \\
\hline AÜZF-43 & 0.23 & 0.08 & 0.00 & 0.01 & 0.01 & 0.05 & 44.33 \\
\hline AÜZF-44 & 0.31 & 0.04 & 0.00 & 0.04 & 0.03 & 0.04 & 46.67 \\
\hline AÜZF-45 & 0.32 & 0.11 & 0.00 & 0.03 & 0.03 & 0.05 & 44.00 \\
\hline AÜZF-46 & 0.32 & 0.03 & 0.00 & 0.01 & 0.02 & 0.05 & 52.00 \\
\hline AÜZF-47 & 0.28 & 0.04 & 0.00 & 0.01 & 0.07 & 0.06 & 45.33 \\
\hline AÜZF-48 & 0.30 & 0.12 & 0.00 & 0.04 & 0.00 & 0.06 & 48.00 \\
\hline AÜZF-49 & 0.34 & 0.04 & 0.00 & 0.00 & 0.07 & 0.05 & 48.00 \\
\hline AÜZF-50 & 0.26 & 0.07 & 0.00 & 0.01 & 0.11 & 0.05 & 49.00 \\
\hline AÜZF-51 & 0.18 & 0.04 & 0.00 & 0.02 & 0.08 & 0.02 & 45.67 \\
\hline AÜZF-52 & 0.29 & 0.03 & 0.00 & 0.02 & 0.07 & 0.08 & 46.00 \\
\hline
\end{tabular}


Çizelge 1'den devam.

\begin{tabular}{|c|c|c|c|c|c|c|c|}
\hline AÜZF-53 & 0.41 & 0.06 & 0.00 & 0.03 & 0.08 & 0.20 & 43.33 \\
\hline AÜZF-54 & 0.40 & 0.11 & 0.00 & 0.04 & 0.03 & 0.10 & 47.00 \\
\hline AÜZF-55 & 0.38 & 0.05 & 0.00 & 0.02 & 0.07 & 0.08 & 50.00 \\
\hline AÜZF-56 & 0.35 & 0.04 & 0.00 & 0.02 & 0.09 & 0.09 & 50.67 \\
\hline AÜZF-57 & 0.32 & 0.05 & 0.00 & 0.01 & 0.07 & 0.07 & 48.67 \\
\hline AÜZF-58 & 0.22 & 0.04 & 0.00 & 0.02 & 0.03 & 0.03 & 43.67 \\
\hline AÜZF-59 & 0.21 & 0.11 & 0.00 & 0.01 & 0.07 & 0.06 & 47.00 \\
\hline AÜZF-60 & 0.25 & 0.05 & 0.00 & 0.01 & 0.05 & 0.05 & 44.33 \\
\hline AÜZF-61 & 0.29 & 0.06 & 0.00 & 0.02 & 0.05 & 0.07 & 42.67 \\
\hline AÜZF-62 & 0.17 & 0.02 & 0.00 & 0.01 & 0.04 & 0.02 & 48.33 \\
\hline AÜZF-63 & 0.32 & 0.05 & 0.00 & 0.04 & 0.03 & 0.04 & 46.67 \\
\hline AÜZF-64 & 0.27 & 0.03 & 0.00 & 0.01 & 0.08 & 0.06 & 46.33 \\
\hline AÜZF-65 & 0.30 & 0.05 & 0.00 & 0.01 & 0.04 & 0.11 & 44.67 \\
\hline AÜZF-66 & 0.25 & 0.04 & 0.00 & 0.02 & 0.03 & 0.04 & 52.33 \\
\hline AÜZF-67 & 0.26 & 0.04 & 0.00 & 0.03 & 0.06 & 0.03 & 48.67 \\
\hline AÜZF-68 & 0.40 & 0.13 & 0.00 & 0.05 & 0.07 & 0.07 & 47.33 \\
\hline AÜZF-69 & 0.24 & 0.05 & 0.00 & 0.04 & 0.05 & 0.03 & 46.67 \\
\hline AÜZF-70 & 0.47 & 0.07 & 0.00 & 0.03 & 0.02 & 0.07 & 45.00 \\
\hline AÜZF-71 & 0.45 & 0.10 & 0.00 & 0.08 & 0.12 & 0.09 & 49.67 \\
\hline AÜZF-72 & 0.25 & 0.14 & 0.00 & 0.05 & 0.07 & 0.10 & 45.33 \\
\hline AÜZF-73 & 0.28 & 0.04 & 0.00 & 0.01 & 0.03 & 0.02 & 44.33 \\
\hline AÜZF-74 & 0.35 & 0.03 & 0.00 & 0.01 & 0.01 & 0.03 & 48.00 \\
\hline AÜZF-76 & 0.39 & 0.05 & 0.00 & 0.02 & 0.01 & 0.03 & 43.33 \\
\hline AÜZF-77 & 0.40 & 0.04 & 0.00 & 0.03 & 0.10 & 0.06 & 48.33 \\
\hline AÜZF-78 & 0.29 & 0.05 & 0.00 & 0.02 & 0.04 & 0.04 & 47.33 \\
\hline AÜZF-79 & 0.21 & 0.04 & 0.00 & 0.02 & 0.01 & 0.04 & 49.67 \\
\hline AÜZF-81 & 0.25 & 0.05 & 0.00 & 0.03 & 0.04 & 0.03 & 47.67 \\
\hline AÜZF-82 & 0.26 & 0.01 & 0.01 & 0.01 & 0.04 & 0.03 & 50.00 \\
\hline AÜZF-83 & 0.29 & 0.04 & 0.00 & 0.01 & 0.12 & 0.06 & 49.00 \\
\hline AÜZF-84 & 0.41 & 0.08 & 0.00 & 0.06 & 0.01 & 0.08 & 48.00 \\
\hline AÜZF-85 & 0.38 & 0.06 & 0.00 & 0.03 & 0.14 & 0.17 & 42.67 \\
\hline AÜZF-86 & 0.31 & 0.07 & 0.00 & 0.03 & 0.17 & 0.10 & 45.33 \\
\hline AÜZF-87 & 0.32 & 0.04 & 0.00 & 0.01 & 0.02 & 0.05 & 44.00 \\
\hline AÜZF-88 & 0.29 & 0.04 & 0.00 & 0.02 & 0.04 & 0.06 & 51.00 \\
\hline AÜZF-89 & 0.30 & 0.03 & 0.00 & 0.01 & 0.04 & 0.05 & 46.67 \\
\hline AÜZF-90 & 0.32 & 0.08 & 0.01 & 0.06 & 0.21 & 0.17 & 46.33 \\
\hline AÜZF-91 & 0.46 & 0.16 & 0.01 & 0.05 & 0.12 & 0.14 & 48.00 \\
\hline AÜZF-92 & 0.39 & 0.12 & 0.01 & 0.07 & 0.15 & 0.11 & 44.67 \\
\hline AÜZF-93 & 0.36 & 0.05 & 0.00 & 0.02 & 0.04 & 0.02 & 49.33 \\
\hline AÜZF-94 & 0.52 & 0.08 & 0.00 & 0.03 & 0.18 & 0.01 & 46.00 \\
\hline AÜZF-95 & 0.30 & 0.03 & 0.00 & 0.02 & 0.10 & 0.09 & 47.33 \\
\hline AÜZF-96 & 0.19 & 0.01 & 0.01 & 0.05 & 0.17 & 0.10 & 44.00 \\
\hline AÜZF-98 & 0.39 & 0.01 & 0.01 & 0.00 & 0.11 & 0.18 & 47.00 \\
\hline AÜZF-99 & 0.35 & 0.00 & 0.00 & 0.01 & 0.01 & 0.12 & 45.33 \\
\hline AÜZF-100 & 0.23 & 0.00 & 0.00 & 0.01 & 0.01 & 0.04 & 49.67 \\
\hline $\begin{array}{l}\text { Çeşitlerin } \\
\text { Ortalaması } \\
\end{array}$ & 0.55 & 0.046 & 0.003 & 0.02 & 0.04 & 0.113 & 48.33 \\
\hline $\begin{array}{l}\text { Genotipleri } \\
\text { n } \\
\text { Ortalaması }\end{array}$ & 0.303 & 0.075 & 0.000 & 0.02 & $\begin{array}{l}0.06 \\
1\end{array}$ & 0.063 & 46.55 \\
\hline $\begin{array}{l}\text { Standart } \\
\text { sapma }\end{array}$ & 0.08 & 0.05 & 0.002 & 0.01 & 0.04 & 0.03 & 2.45 \\
\hline$T$ değeri & 0.02 & 0.03 & 0.005 & 0.01 & 0.05 & 0.09 & 0.57 \\
\hline P Değeri & $0.00^{*}$ & $0.00^{*}$ & $0.00^{*}$ & $\begin{array}{l}0.03 * \\
*\end{array}$ & $\begin{array}{l}0.00 \\
*\end{array}$ & $0.00 *$ & $0.00 *$ \\
\hline
\end{tabular}

$* * \mathrm{p}<0.05$ düzeyinde önemlidir, ${ }^{*} \mathrm{p}<0.01$ düzeyinde önemlidir. 
Çeşit ve genotiplerin, ortalama papaverin oranı değerleri karşılaştırıldığında anlamlı bir fark bulunmuştur. Çeşitlerin papaverin oranı değeri \% 0.01 0.1 arasında, genotiplerin papaverin oranı değeri \% 0.0 0.21 arasında değişmiştir. Genotipler arasında en yüksek papaverin oranı değeri \% 0.21 ile AÜZF-90 no'lu, en düşük papaverin oranı ise AÜZF 48 no'lu genotip de bulunmuştur. Denemede 54 adet genotip çeşitlerin ortalama papaverin oranı değeri (\% 0.04) üzerinde yer almıştır. Subrtova ve ark. (1989), seçilmiş haşhaş populasyonlarında 25 haşhaş çeşidinde yapmış oldukları denemede papaverin içeriğinin ise 11 genotipte ölçülebilecek miktarlarda olmadığını en yüksek değerini ise $\% 0.3$ olarak bulmuşlardır.

Çeşit ve genotiplerın ortalama noscapin oranı değerleri karşılaştırıldığında istatistiksel olarak önemli bulunmuştur. Çeşitlerin noscapin oranları değerleri \% 0.02-0.20 arasında, genotiplerın noscapin oranı değerleri $\%$ 0.01-0.20 arasında değişmiştir. En yüksek noskapin oranı AÜZF 53 no'lu genotip ile Ayfon 95 çeşidinde, en düşük Noskapin oranı ise AÜZF 94 no'lu genotiplerde bulunmuştur. Araştırmada 8 adet hat çeşitlerin ortalama noscapin oranı değeri (\% 0.11) üzerinde yer almıştır.

Çeşit ve genotiplerin ortalama yağ oranı değerleri karşılaştırıldığında istatistiksel olarak anlamlı bir fark bulunmuştur. Çeşitlerin yağ oranları değerleri \% 48-49 arasında, genotiplerin yağ oranı değerleri \% $40-53$ arasında değişmiştir. Genotipler arasında en yüksek yağ oranı değeri \% 53 ile AÜZF-4 no'lu genotip olmuştur. Araştırmada 19 adet genotip, çeşitlerin ortalama yağ oranı değeri (\% 48) üzerinde yer almıştır.

Arslan (2000), değişik yörelerinden toplanan haşhaş numunelerinde 325 adet populasyonun yağ oran değerlerini \% 38.86-53.39 arasında bulmuştur. Çalışmamız bu araştırma ile benzer sonuçlar göstermiştir.

\section{SONUÇ}

Sonuç olarak incelenen 3 adet haşhaş çeşidi ile 94 adet haşhaş hattının, morfin oranı bakımından AÜZF-22 no'lu kodein oranı bakımından AÜZF-5 no'lu, oripavin oranı bakımından AÜZF-11, AÜZF-82, AÜZF-90, AÜZF-91, AÜZF-92, AÜZF-96, AÜZF-98 no'lu, tebain oranı bakımından AÜZF-20 ve 71 no'lu, papaverin oranı bakımından AÜZF-90 no'lu, noscapin oran1 bakımından AÜZF-53 no'lu ve yağ oranı bakımından AÜZF-4 no'lu genotiplerının ön plana çıktığı görülmüştür. Belirlenen bu genotipler üzerinde sslah çalışmaları yapılarak alkaloid (morfin, kodein, oripavin, tebain, noskapin ve papaverin) ve yağ oranları daha yüksek çeşitler geliştirilebilir. Ayrıca alkaloid oranı düşük, tohum ve kapsül verimi yüksek genotipler üzerinde ıslah çalışmaları yapılarak sadece tohumluk üretiminde kullanılmak üzere çeşit geliştirilebilir.

\section{TEŞEKKÜR}

Bu makale Tarımsal Araştırmalar ve Politikalar Genel Müdürlügü tarafindan desteklenen projeden üretilmiştir. TAGEM'e teşekkür ederiz.

\section{KAYNAKLAR}

Anonim 2015. 2014 Y1lı Haşhaş Sektör Raporu. http://tarim.kalkinma.gov.tr/wpcontent/uploads/2015/12/2014 hashaşsektorraporu.pdf, (Erişim Tarihi: 15.08.2017). Anonim 2017. 2016 Yılı Haşhaş Sektör Raporu. Toprak Mahsulleri Ofisi Genel Müdürlügüü. http://www.tmo.gov.tr/Upload/Document/hashassekt rraporu.pdf, (Erişim Tarihi: 15.08.2017).

Arslan N, Büyükgöçmen R, Gümüşçü A 2000. Oil and Morphine Contents of Turkish Poppy Populations. Field Crops Central Research Institute Journal. (9), 1-2 2000

Aytekin M 2005. “Azot ve Fosfor Dozlarının Haşhaşta Verim ve Verim Unsurlar İle Kalite Üzerine Etkileri”. Selçuk Üniversitesi Fen Bilimleri Enstitüsü, Yüksek Lisans Tezi, Konya.

Erdurmuş A 1989. In Poppy Lines (Papaver somniferum L.) Relationships With The Morphine and Seed Yield of Phonological and Morphological Characters. PhD Thesis, Graduate School of Natural and Applied Sciences, Ankara University-Ankara.

Kahraman M 2011. Policies Implemented on Poppy in Turkey and Poppy Importance for Turkey. Namik Kemal University, Institute of Science and Technology, Department of Agricultural Economics, Master Thesis, Aydın.

Novak J, Strakova V 1989. Evaluation of Selected Poppy (Papaver somniferum L.) Varieties. Rostlinna Vyroba. Vysoka Skola Zemedelska, 16521 Prague, 6- Suchdol, Czechoslovakia.

Subtrova D, Rehakova V, Hubacek J, Pondelik P 1989. Contents of The Major Alkoloids Selected Cultivars of Opium Poppy. Sbornik, Vyseke, Skoly, Zemedelske- Praze, Fakulta, Agronomica. 51:65-83. Plant Breeding Abstract 1991: 061-06497. 